\title{
Introduction to Hanefeld Symposium: 40+ years of metabolic syndrome
}

\author{
Christian A. $\operatorname{Koch}^{1} \cdot$ Stefan R. Bornstein ${ }^{2,3}$ • Andreas L. Birkenfeld ${ }^{2,3,4,5}$
}

Published online: 11 May 2016

(C) Springer Science+Business Media New York 2016

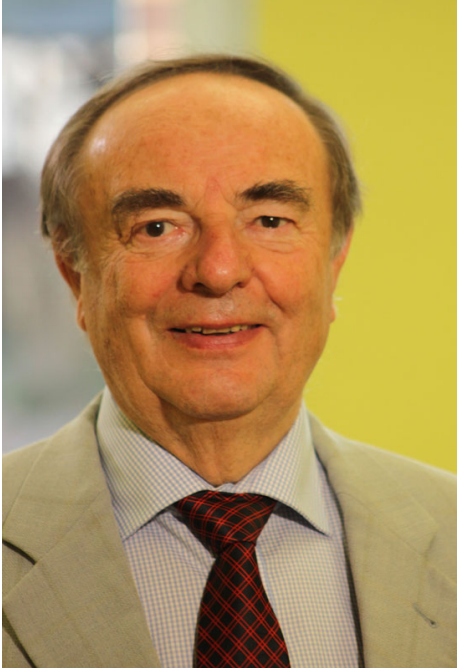

Markolf Hanefeld, MD, Dr. hc. PhD, is Professor of Internal Medicine, Endocrinology and Diabetology (Diabetologist DDG)

Andreas L. Birkenfeld

Andreas.birkenfeld@uniklinikum-dresden.de

1 University of Mississippi Medical Center, Jackson, MS, USA

2 Medizinische Klinik III, Universitätsklinikum Carl Gustav Carus TU Dresden, Fetscherstr. 74, 01307 Dresden, Germany

3 Section of Diabetes and Nutritional Sciences, Rayne Institute, Denmark Hill Campus, King's College London, London, UK

4 Competence Center Metabolic Vascular Medicine Prof. Hanefeld, GWT-TUD, Dresden, Germany

5 German Center for Diabetes Research (DZD e.V.), Neuherberg, Germany
In honor of Professor Markolf Hanefeld's 80th birthday, a special symposium had been held in Dresden, Germany, where Prof. Hanefeld spent most of his professional career. This special Guest issue comprises articles of prominent scientists, many of whom collaborators of Prof. Hanefeld, working in medical research areas / fields related to metabolic syndrome.

Prof. Hanefeld started his outstanding academic career in the early sixties at the Medical Academy 'Carl Gustav Carus' in Dresden, at a time when the wall was build up in Berlin. Dresden had a long tradition of structured diabetes care with the first outpatient department in Europe initiated by O. Rostoski in 1923. Under the guidance of his teacher H. Haller, this group started comprehensive studies on the interaction of non-alcoholic fatty liver and metabolic dysregulation with the major finding that fatty liver was intricately connected with abnormal glucose tolerance, dyslipidemia, hyperuricemia and obesity [1]. On this basis, together with W. Leonhardt, Prof. Hanefeld in 1981 published the first comprehensive definition of the metabolic syndrome as a cluster of metabolic diseases and hypertension with increased risk of diabetes mellitus and cardiovascular disease (CVD) [2]. The emphasis of this concept, which is valid until today, was on an integrated approach for diagnostics and therapy with lifestyle intervention as a common tool to prevent diabetes mellitus and CVD in people with the metabolic syndrome. In parallel with the UK-PDS, Prof. Hanefeld initiated the Diabetes Intervention Study (DIS) in patients with newly diagnosed type 2 diabetes, to evaluate the efficacy of life style intervention and risk factor control on cardiovascular outcome. This study, with postprandial (pp) measurements, identified the quality of pp glucose control, pp triglycerides and blood pressure as independent risk factors for CVD and all cause mortality $[3,4]$. 
In 1973, Prof. Hanefeld started the first outpatient department for lipid diseases in Eastern Germany, which later became the coordinating center for clinical lipid research together with the Anitschkov Institute in Leningrad (Prof. A.N. Klimov) of the Eastern Block countries. To build a bridge to international research, Prof. Hanefeld initiated together with H. Haller and W. Jaross the First International Dresden Lipid Symposium in 1973, which continued up to 1993 as meeting point for scientists of the Eastern Block with colleagues from the West. After the fall of the Berlin wall in 1989, Prof. Hanefeld was a leading investigator in international studies with focus on pp hyperglycemia and the metabolic syndrome. In the STOP-NIDDM trial (Leader J.L. Chiasson), his group showed that control of pp hyperglycemia in people with impaired glucose tolerance not only reduces the incidence of newly diagnosed diabetes mellitus and CVD, but also the incidence of hypertension $[5,6]$.

Picture insert Cancun, Mexico, showing Markolf Hanefeld, Sir Randle, Steven Haffner, Harold Lebovitz, Ralph deFronzo, Ronald C. Kahn, Eberhard Standl, Itamar Raz and other authors of this special REMD guest issue.

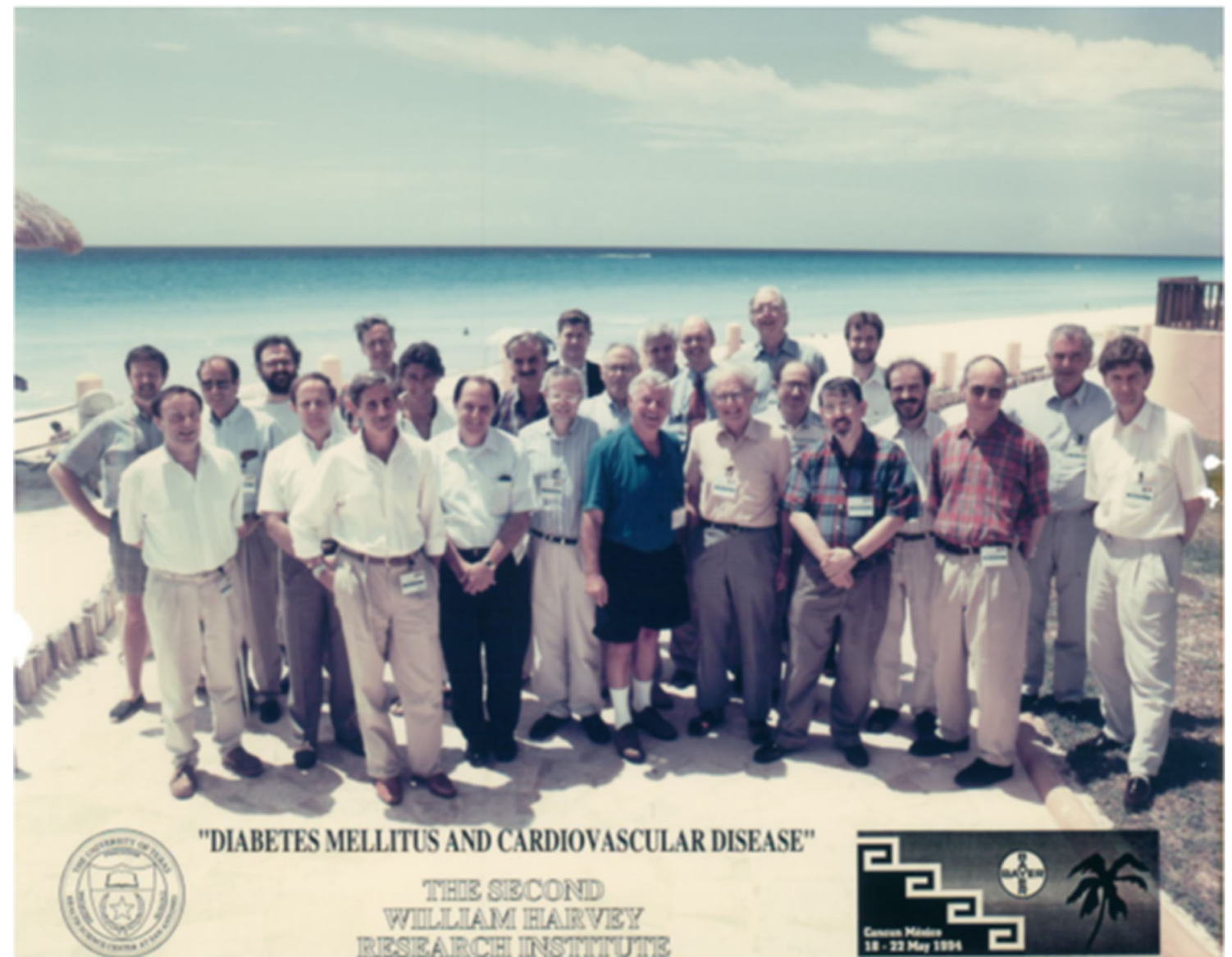

A further landmark study was the Risk Factors in IGT for Atherosclerosis and Diabetes (RIAD) Study [7], which demonstrated a clear association between different traits of the metabolic syndrome with atherosclerotic lesions. For his outstanding research in this field and his continuous commitment to metabolic research, Prof. Hanefeld received numerous honors and awards, including the presidency of the
International Atherosclerosis Society and the Paul Langerhans Medal of the German Diabetes Association.

Prof. Hanefeld is still an active scientist. He served as a steering committee member of the ORIGIN study testing the effect of early basal insulin initiation on cardiovascular events, and he was the national coordinator of TECOS, evaluating the cardiovascular safety of the DPP-4 inhibitor sitagliptin in type 
2 diabetic patients. Prof. Hanefeld recently also pioneered important real world studies assessing the connection between hypoglycemia and acute cardiovascular risk, providing evidence for an association of hypoglycemia with ventricular arrhythmias $[8,9]$. Moreover, Prof. Hanefeld is the father of three daughters and a passionate dancer, long distance runner, and gardener, and organizes conventions bridging the gap between science and art.

Prof. Hanefeld not only treated thousands of patients but coined and pioneered the concept of the metabolic syndrome which forms today the basis of the management of millions of patients suffering from this common disorder.

This special Guest issue begins with an inaugural article by the guest editors on the guest issue theme "Metabolic vascular syndrome" [10], followed by Profs. Jordan's and Birkenfeld's review on the cardiometabolic crosstalk in obesity-associated arterial hypertension [11], an important part of endocrine hypertension [12]. A better understanding of the interaction between the immune system and the endocrine system including the adipose issue is provided by the immunology expert group around Prof. Chavakis $[13,14]$. Inasmuch perivascular adipose tissue plays a role in the metabolic syndrome is reviewed by Profs. Siegel-Axel and Haering [15]. The rates of obesity with its heterogeneous and complex causes have rapidly increased over the last three decades. Genetic factors may account for 40 to $70 \%$ of the variability in obesity among individuals and investigators propose environmental signals such as ambient temperature as possible modulator of the on-off obesity phenotype [16]. Prof. Koch and colleagues briefly review the effect of ambient temperature on metabolic rate and adipose tissue [17]. Prof. Lebovitz reviews gastric electrical stimulation as a tool to treat obesity, type 2 diabetes, and hypertension [18]. Lifestyle intervention is an important aspect in treating patients with the metabolic syndrome. A recent systematic review with meta-analysis, using Cochrane methods, examined seven behavioural outcomes including smoking cessation, diet, and physical activity, to see whether communicating DNA based disease risk would motivate risk-reducing behavior and found it did not [19]. Prof. Malin and colleagues examined how some of the prediabetes phenotypes appear resistant to traditional exercise interventions [20]. Profs. Monnier, Skrha, and Ceriello and their colleagues review the importance of reducing overall hyperglycemia [21-23]. As CVD is the leading cause for mortality in patients with diabetes mellitus, it is important to prevent or treat it appropriately. Prof. Raz and colleagues review outcome studies of cardiovascular risk factors other than diabetes mellitus and their impact on current treatment guidelines for patients with diabetes [24]. The concluding article of this guest issue is provided by epidemiologist Prof. Rothe and colleagues on determinants of mortality in patients with type 2 diabetes [25].

\section{References}

1. Leonhardt W, Hanefeld M, Julius U, Haller H. Significance of fatty tissue hypertrophy for the metabolic risk. Z Gesamte Inn Med. 1977;32((12):suppl):186-7.

2. Hanefeld M, Leonhardt W. Das Metabolische Syndrom. Deutsche Gesundheitswesen. 1981;36:545-51.

3. Hanefeld M, Fischer S, Julius U, Schulze J, Schwanebeck U, Schmechel H, et al. Risk factors for myocardial infarction and death in newly detected NIDDM: the Diabetes Intervention Study, 11year follow-up. Diabetologia. 1996;39(12):1577-83.

4. Hanefeld M, Schmechel H, Schwanebeck U, Lindner J. Predictors of coronary heart disease and death in NIDDM: the Diabetes Intervention Study experience. Diabetologia. 1997;40 Suppl 2: S123-4.

5. Hanefeld M, Pistrosch F, Koehler C, Chiasson JL. Conversion of IGT to type 2 diabetes mellitus is associated with incident cases of hypertension: a post-hoc analysis of the STOP-NIDDM trial. J Hypertens. 2012;30(7):1440-3.

6. Hanefeld M, Karasik A, Koehler C, Westermeier T, Chiasson JL. Metabolic syndrome and its single traits as risk factors for diabetes in people with impaired glucose tolerance: the STOP-NIDDM trial. Diab Vasc Dis Res. 2009;6(1):32-7.

7. Hanefeld M, Koehler C, Henkel E, Fuecker K, Schaper F, Temelkova-Kurktschiev T. Post-challenge hyperglycaemia relates more strongly than fasting hyperglycaemia with carotid intimamedia thickness: the RIAD Study. Risk Factors in Impaired Glucose Tolerance for Atherosclerosis and Diabetes. Diabet Med. 2000;17(12):835-40.

8. Stahn A, Pistrosch F, Ganz X, Teige M, Koehler C, Bornstein S, et al. Relationship between hypoglycemic episodes and ventricular arrhythmias in patients with type 2 diabetes and cardiovascular diseases: silent hypoglycemias and silent arrhythmias. Diabetes Care. 2014;37(2):516-20.

9. Pistrosch F, Ganz X, Bornstein SR, Birkenfeld AL, Henkel E, Hanefeld M. Risk of and risk factors for hypoglycemia and associated arrhythmias in patients with type 2 diabetes and cardiovascular disease: a cohort study under real-world conditions. Acta Diabetol. 2015;52(5):889-95.

10. Hanefeld M, Pistrosch F, Bornstein SR, Birkenfeld AL. The metabolic vascular syndrome - guide to an individualized treatment. Rev Endocr Metab Disord. 2016.

11. Jordan J, Birkenfeld AL. Cardiometabolic crosstalk in obesityassociated arterial hypertension. Rev Endocr Metab Disord. 2016.

12. Endocrine Hypertension. In: Koch CA, Chrousos GP, editors. Contemporary Endocrinology Series. Springer, New York; 2013. ISBN: 978-1-60761-547-7 (Print), ISBN-10: 978-1-60761-548-4 (online).

13. Nati M, Haddad D, Birkenfeld AL, Koch CA, Chavakis T, Chatzigeorgiou A. The role of immune cells in metabolismrelated liver inflammation and development of non-alcoholic steatohepatitis (NASH). Rev Endocr Metab Disord. 2016.

14. Alexaki VI, Chavakis T. The role of innate immunity in the regulation of brown and beige adipogenesis. Rev Endocr Metab Disord. 2016. 
15. Siegel-Axel DI, Häring HU. Perivascular adipose tissue: an unique fat compartment relevant for the cardiometabolic syndrome. Rev Endocr Metab Disord. 2016.

16. Dalgaard K, Landgraf K, Heyne S, Lempradl A, Longinotto J, Gossens K, et al. Trim28 Haploinsufficiency Triggers Bi-stable epigenetic obesity. Cell. 2016;164(3):353-64.

17. Turner JB, Kumar A, Koch CA. The effects of indoor and outdoor temperature on metabolic rate and adipose tissue - The Mississipppi perspective on the obesity epidemic. Rev Endocr Metab Disord. 2016, in press.

18. Lebovitz HE. Interventional treatment of obesity and diabetes: an interim report on gastric electrical stimulation. Rev Endocr Metab Disord. 2016.

19. Hollands GJ, French DP, Griffin SJ, Prevost AT, Sutton S, King S, et al. The impact of communicating genetic risks of disease on riskreducing health behaviour: systematic review with meta-analysis. BMJ. 2016;352:11102.

20. Malin SK, Liu Z, Barrett EJ, Weltman A. Exercise resistance across the prediabetes phenotypes: impact on insulin sensitivity and substrate metabolism. Rev Endocr Metab Disord. 2016.

21. Monnier L, Colette C, Dejager S, Owens DR. Near normal HbA1c with stable glucose homeostasis: the ultimate target / aim of diabetes therapy. Rev Endocr Metab Disord. 2016.

22. Škrha J, Šoupal J, Škrha J Jr, Prázný M. Glucose variability, HbA1c and microvascular complications. Rev Endocr Metab Disord. 2016.

23. Ceriello A, Genovese SA. Atherogenicity of postprandial hyperglycemia and lipotoxiticy. Rev Endocr Metab Disord. 2016.

24. Cahn A, Cernea S, Raz I. Outcome studies and safety as guide for decision making in treating patients with type 2 diabetes. Rev Endocr Metab Disord. 2016.

25. Engelmann J, Manuwald U, Rubach C, Kugler J, Birkenfeld AL, Hanefeld M, et al. Determinants of mortality in patients with type 2 diabetes: a review. Rev Endocr Metab Disord. 2016.

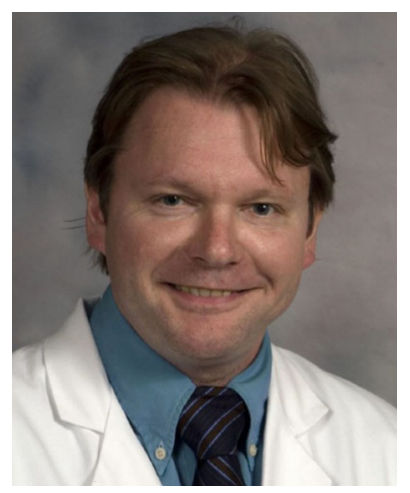

Prof. Christian A. Koch's research and clinical interest areas include the molecular pathogenesis of (neuro)endocrine tumors (pituitary, thyroid, adrenal glands, GEP-NET, multiple endocrine neoplasia syndromes) and endocrine hypertension. Prof. Koch trained in neurosurgery, neurology, and internal medicine in Germany, and completed a residency in Internal Medicine at the Ohio State University in Columbus, OH, USA, under the chairmanship of Prof. EL

Mazzaferri, and clinical and research training in endocrinology at the National Institutes of Health in Bethesda, MD, under the guidance of Prof. George P. Chrousos. In 2002, Koch returned to Germany and joined the division of Prof. Ralf Paschke (since 2004 Prof. M. Stumvoll) as C2 faculty Oberarzt at the University of Leipzig and then Adjunct Associate Professor at Georgetown University, before taking on the position as director of the division of endocrinology at the University of Mississippi in Jackson, MS, in 2006, a position he has held until 2013, when he obtained tenure. Prof. Koch's focus remains translational and multidisciplinary research with questions arising from patient encounters, trying to explain clinical observations by looking at "bench" results to further improve patient care.

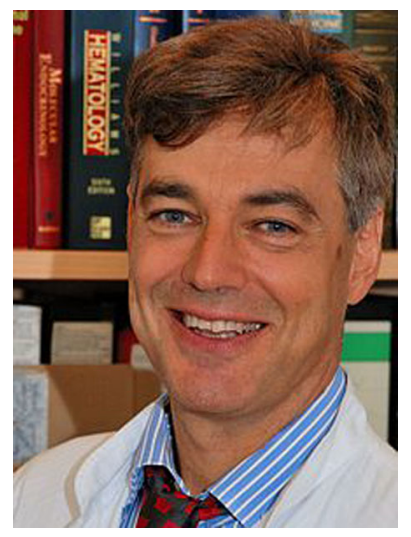

Prof. Stefan R. Bornstein graduated from the University of Ulm and Miami in 1988. He completed his residency in internal medicine in 1994 and specialized in endocrinology and diabetes. He won several awards including the first prize for "The new generation of academics" and the MariusTausk-Award of the German Endocrine Society. As a recipient of the Heisenberg Award of the German Research Foundation (DFG), Prof. Bornstein has been working for many years as a research scholar and then acting unit chief at the endocrine branch at the National Institutes of Health in Bethesda, United States. From 2001 to 2004, he was Professor and vice-chair of the department of endocrinology and metabolism at the University of Düsseldorf, Germany. Since 2004, Prof. Bornstein has been Director and Chair of the Department of Medicine at the University of Dresden, Germany. In 2012, he became Dean of International Affairs and Development at the University of Dresden and was appointed Chair and Honorary Consultant, Endocrinology and Diabetes, King's College London, in 2013. In March 2015, Prof. Bornstein became Transcampus Dean of King's College London and the University of Dresden. His main research interests focus on lipid-, steroidand catecholamine metabolism, immune endocrine crosstalk, type 1 diabetes, islet transplantation and mechanisms of hypertension in the metabolic syndrome.

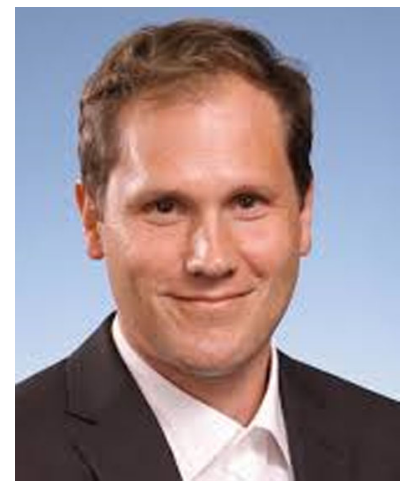

Prof. Andreas L. Birkenfeld's research and clinical interests focus on the treatment and the initial steps in the development of obesity and type 2 diabetes and the metabolic vascular syndrome as well as its impact on ageing. Prof. Birkenfeld completed a residency in Internal Medicine and Cardiology at the Charité University School of Medicine, Berlin, Germany, under the chairmanship of Prof. Friedrich Luft. He completed his thesis on the interaction of metabolic and autonomic nervous system regulation (Mentor: Prof. Jens Jordan), and performed a postdoctoral fellowship at the Yale University School of Medicine with Prof. Gerald I Shulman in the Department of Endocrinology and Cellular and Molecular Physiology. Birkenfeld then returned to Germany to the German Institute of Human Nutrition and the Charite - University School of Medicine in Berlin in the Department of Diabetes, Endocrinology and Nutrition, where he received his first tenure position. Since 2014, Prof. Birkenfeld leads the Section of Metabolic Vascular Medicine at the University Clinic Carl Gustav Carus Dresden and is the Director of the Competence Center Metabolic Vascular Medicine Prof. Hanefeld, of the GWT-TUD. In 2015, Prof. Birkenfeld was appointed as a Transcampus Professor of Diabetes at King's College London, UK. 